1. de Bruyne MC, Hoes AW, Kors JA, Hofman A, van Bemmel JH, Grobbee DE. QTc dispersion predicts cardiac mortality in the elderly. Circulation 1998;97: 467-472.

2. Okin PM, Devereux RB, Howard BV, Fabsitz RR, Lee ET, Welty TK. Assessment of QT interval and QT dispersion for prediction of all-cause and cardiovascular mortality in American Indians. Circulation 2000;101:61-66. 3. Fu GS, Meissner A, Freeman R, Simon R. Repolarization dispersion and sudden cardiac death in patients with impaired left ventricular function. Eur Heart J 1997;18:281-289.

4. Barr CS, Naas A, Freeman M, Lang CC, Struthers AD. QT dispersion and sudden unexpected death in chronic heart failure. Lancet 1994;343:327-329. 5. Buja G, Miorelli M, Turrini P, Melacini P, Nava A. Comparison of QT dispersion in hypertrophic cardiomyopathy between patients with and without ventricular arrhythmias and sudden cardiac death. Am J Cardiol 1993;72:973976.

6. Yildirir ASE, Tokgozoglu L, Oto A. The effects of chronic carvedilol therapy on QT dispersion in patients with congestive heart failure. Eur J Heart Failure 2001;3:717-721.
7. Fesmire SI, Marcoux LG, Lyyski DS, Sprague MK, Kennedy HL, Eichhorn EJ. Effect of selective versus nonselective beta blockade on QT dispersion in patients with nonischemic dilated cardiomyopathy. Am J Cardiol 1999;84:350-354. 8. Mesquita ET, Deus FC, Guedes CR, Maia ER, Subieta CGP, Villacorta H, Alessandra dos Santos PA, Cramer H, Amado dos Santos VB, Romeo LJM Effects of propranolol on the QT dispersion in congestive heart failure. Arq Bras Cardiol 1999;73:295-298.

9. Bonnar CE, Davie AP, Caruana L, Fenn L, Ogston SA, McMurray JJV Struthers AD. QT dispersion in patients with chronic heart failure: beta blockers are associated with a reduction in QT dispersion. Heart 1999;81:297-302.

10. Peng DQ, Zhao SP, Chen Y, Li XP. Effect of bisoprolol on QT dispersion in patients with congestive heart failure. Int J Cardiol 2001;77:141-148.

11. Bristow M, Gilbert E, Abraham W, Adams K, Fowler M, Hershberger R, Kubo S, Narahara K, Ingersoll H, Krueger S, et al. Carvedilol produces doserelated improvements in left ventricular function and survival in subjects with chronic heart failure. Circulation 1996;94:2807-2816.

12. Cowan JC, Yusoff K, Moore M, Amos PA, Gold AE, Bourke JP, Tansuphaswadikul S, Campbell RWF. Importance of lead selection in QT interval measurement. Am J Cardiol 1988;61:83-87.

\title{
Effect of Cardiac Resynchronization Therapy on Functional Mitral Regurgitation in Heart Failure
}

\author{
Patrizio Lancellotti, MD, Pierre Mélon, MD, Natzi Sakalihasan, MD, André Waleffe, MD, \\ Christophe Dubois, MD, Michel Bertholet, MD, and Luc A. Piérard, MD
}

Cardiac resynchronization therapy (CRT) reduces functional mitral regurgitation (MR) at rest. This study assessed exercise-induced changes in MR in patients with heart failure who were helped by CRT. The determinants of these exercise-induced changes in MR were analyzed in asynchronous and resynchronized left ventricles. $\bigcirc 2004$ by Excerpta Medica Inc. (Am J Cardiol 2004;94:1462-1465)

C ardiac resynchronization therapy (CRT) with biventricular pacing has emerged as a new approach for treating patients with heart failure and significant ventricular conduction delay and/or dyssynchrony. ${ }^{1-3}$ CRT improves left ventricular systolic and diastolic function ${ }^{4}$ and clinical status ${ }^{5}$ and reduces functional mitral regurgitation (MR). ${ }^{6}$ Whether CRT significantly affects exercise-induced changes in MR has never been investigated. This study examined the effects of CRT on MR and assessed the determinants of exercise-induced changes in MR under biventricular pacing.

This prospective study included 27 consecutive patients with heart failure who were clinically helped by biventricular pacing. Before CRT implantation, all were in New York Heart Association class III and had left ventricular ejection fractions $\leq 35 \%$, functional $\mathrm{MR}$, were in sinus rhythm, had QRS duration $\geq 140 \mathrm{~ms}$, and had interventricular delay (the time interval between aortic and pulmonary valve opening) $\geq 50 \mathrm{~ms}$. All patients underwent quantitative exercise Doppler echocardiography with and without active CRT. The causes of

From the Departments of Cardiology and Cardiovascular Surgery, University Hospital of Liège, Liège, Belgium. Dr. Piérard's address is: Department of Cardiology, University Hospital of Liège, B-4000 Liege, Belgium. E-mail: Ipierard@chu.ulg.ac.be. Manuscript received June 4, 2004; revised manuscript received and accepted July 27, 2004. heart failure were idiopathic dilated cardiomyopathy in 9 patients and ischemic heart disease in 18 . The protocol was approved by the human ethical committee of our university hospital, and all patients gave informed consent.

A symptom-limited graded bicycle exercise test was performed in a semisupine position on a tilting exercise table. After an initial workload of $25 \mathrm{~W}$ maintained for 2 minutes, the workload was increased every 2 minutes by $25 \mathrm{~W}$. Blood pressure and 12-lead electrocardiograms were recorded every 2 minutes. Two-dimensional and Doppler echocardiographic recordings were available throughout the test.

Baseline and exercise echocardiographic studies were performed $45 \pm 16$ days after implantation of the CRT system using the phased-array Acuson Sequoia (Siemens AG, Munich, Germany) or VIVID 7 (GE Healthcare, Little Chalfont, United Kingdom) imaging device. In 17 patients, after data acquisition during active CRT (CRT on), pacing was interrupted during 30 minutes before data acquisition during intrinsic conduction (CRT off). In the other 10 patients, data were first acquired with CRT off. All echocardiographic and Doppler recordings were obtained in digital format and stored on optical discs for off-line analysis. For each measurement, $\geq 3$ cardiac cycles were averaged. The quantitation of MR was performed by the quantitative Doppler method using mitral and aortic stroke volumes and the proximal isovelocity surface area method, as previously described.7,8 The results of these 2 methods were averaged, allowing the calculation of regurgitant volume and the effective regurgitant orifice (ERO). Left ventricular end-diastolic and end-systolic volumes and ejection fractions were measured by the bi-apical Simpson disk method. The left ventricular $\mathrm{dP} / \mathrm{dt}$ was estimated from the steepest increasing segment of the continuous- 
TABLE 1 Effects of CRT at Rest

\begin{tabular}{|lccc|}
\hline & \multicolumn{2}{c}{ CRT } & \\
\cline { 2 - 3 } Variable & Off & On & p Value \\
\hline Heart rate (beats/min) & $71 \pm 7$ & $70 \pm 8$ & NS \\
End-diastolic volume (ml) & $203 \pm 37$ & $197 \pm 35$ & 0.0028 \\
End-systolic volume (ml) & $145 \pm 33$ & $136 \pm 29$ & 0.0003 \\
Left ventricular ejection fraction (\%) & $29 \pm 5$ & $31 \pm 4$ & 0.0017 \\
Effective regurgitant orifice (mm $\left.{ }^{2}\right)$ & $22 \pm 10$ & $13 \pm 7$ & 0.00001 \\
Left ventricular dP/dt (mm Hg/s) & $572 \pm 107$ & $853 \pm 154$ & 0.00065 \\
Transtricuspid pressure gradient $(\mathrm{mm} \mathrm{Hg})$ & $34 \pm 9$ & $25 \pm 8$ & 0.00022 \\
\hline
\end{tabular}

TABLE 2 Effects of CRT During Exercise

\begin{tabular}{|lccc|}
\hline & \multicolumn{2}{c}{ CRT } & \\
\cline { 2 - 3 } Variable & Off & On & p Value \\
\hline Heart rate (beats/min) & $113 \pm 8$ & $115 \pm 9$ & NS \\
Test duration (minutes) & $4.4 \pm 1.1$ & $4.9 \pm 0.9$ & 0.0027 \\
Load (W) & $61 \pm 13$ & $70 \pm 16$ & 0.02 \\
End-diastolic volume (ml) & $200 \pm 36$ & $194 \pm 31$ & 0.023 \\
End-systolic volume (ml) & $136 \pm 28$ & $126 \pm 23$ & 0.0007 \\
Left ventricular ejection fraction (\%) & $32 \pm 4$ & $35 \pm 5$ & 0.0005 \\
Effective regurgitant orifice $\left(\mathrm{mm}^{2}\right)$ & $37 \pm 12$ & $19 \pm 8$ & 0.00001 \\
Left ventricular dP/dt (mm Hg/s) & $675 \pm 123$ & $1,009 \pm 197$ & 0.0004 \\
Transtricuspid pressure gradient $(\mathrm{mm} \mathrm{Hg})$ & $54 \pm 12$ & $37 \pm 8$ & 0.0001 \\
\hline
\end{tabular}

TISTICA, version 5, StatSoft, Inc., Tulsa, Oklahoma). A p value of $<0.05$ was considered significant. Linear regression analysis was applied to calculate the correlations between ERO at rest and at exercise and the percentage of increase in left ventricular $\mathrm{dP} / \mathrm{dt}$ and changes in mitral valvular deformation. The reproducibility of echocardiographic measurements has been previously published. , $^{11}$

No patient included was pacing dependent. At the time of echocardiography, all patients were in sinus rhythm and had, by definition, an improvement of $\geq 1$ New York Heart Association class. The QRS duration decreased from $160 \pm 15 \mathrm{~ms}$ at baseline to $139 \pm 22 \mathrm{~ms}$ ( $\mathrm{p}<0.001)$ under biventricular pacing.

CRT-induced changes in echocardiographic parameters are listed in Table 1. During biventricular pacing, heart rate did not change, left ventricular end-diastolic and end-systolic volumes decreased $(\mathrm{p}<0.01)$, left ventricular systolic function as

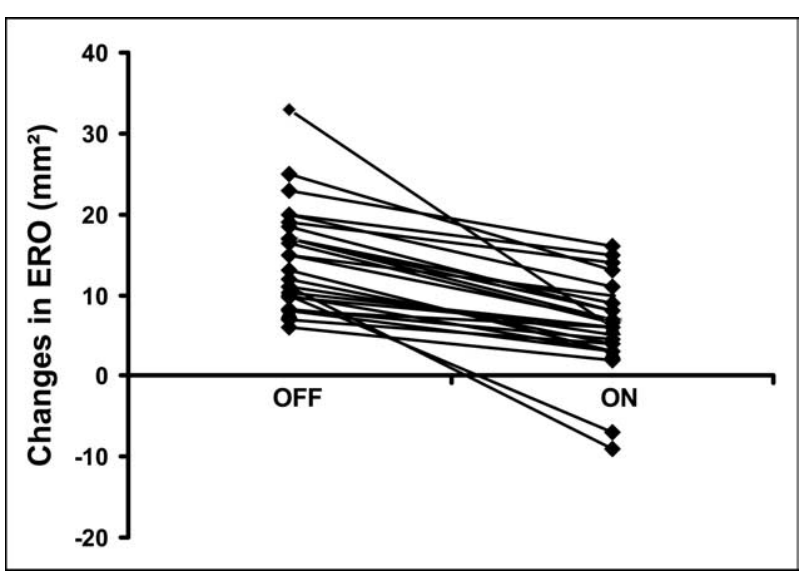

FIGURE 1. Patient exercise-induced changes in ERO with CRT off and CRT on. ERO increased in all but 2 patients with CRT on. However, the increase in ERO was less with CRT on.

wave Doppler regurgitant jet, as previously described. ${ }^{9}$ Valvular tenting area was obtained from the parasternal long-axis view at mid-systole and measured the area enclosed between the annular plane and the mitral leaflets. ${ }^{10,11}$

All patients received biventricular pacing devices for CRT, with a right ventricular apical lead and left ventricular pacing electrodes positioned through the coronary sinus in a left ventricular epicardial vein. This coronary sinus lead was placed in a lateral position in 21 patients $(77 \%)$, in a posterior position in 4 patients, and in an anterior position in 2 patients. The device was programmed in DDD mode with a fixed atrioventricular delay.

Data are expressed as means \pm 1 SD. Paired data were analyzed with Wilcoxon's signed-rank test (STA- estimated by left ventricular $\mathrm{dP} / \mathrm{dt}$ and ejection fraction improved, and transtricuspid pressure gradient and the severity of MR decreased. ERO decreased in all patients $(\mathrm{p}=0.00001)$. CRT-induced changes in ERO were correlated with the percentage of increase in left ventricular $\mathrm{dP} / \mathrm{dt}(\mathrm{r}=-0.72, \mathrm{p}=0.00003)$. With CRT on, functional MR was correlated with the mitral systolic tenting area $(r=0.65, p=0.0002)$, whereas the correlation was not significant with CRT off ( $r=0.37, p=N S)$. Left ventricular $\mathrm{dP} / \mathrm{dt}$ was not related to tenting area in any mode.

CRT-induced changes in echocardiographic parameters during exercise are listed in Table 2. Exercise duration was greater with CRT on. During testing, heart rate increases from at rest to peak exercise were not affected by CRT. Compared with CRT off, changes in left ventricular end-diastolic and end-systolic volumes and ejection fraction observed at rest with CRT on were maintained at exercise (CRT off vs CRT on, $p<0.05$ ). During exercise and in the 2 pacing conditions, left ventricular end-diastolic volume remained unchanged, whereas endsystolic volume decreased $(\mathrm{p}<0.001)$ and ejection fraction increased $(p<0.0001)$. Although the transtricuspid pressure gradient increased in the 2 modes during exercise, the increment was less with CRT on $(p=0.0001)$.

During exercise, ERO increased in all patients with CRT off from $22 \pm 10$ (range 11 to 44 ) to $37 \pm 12 \mathrm{~mm}^{2}$ (range 16 to $66 ; \mathrm{p}<0.001$ ). With CRT on, ERO increased in 25 patients from $12 \pm 7 \mathrm{~mm}^{2}$ at rest (range 2 to 24 ) to $20 \pm 8 \mathrm{~mm}^{2}$ during exercise (range 8 to $33 ; \mathrm{p}$ $=0.0015)$ and decreased in the 2 remaining patients. The increase in ERO was less during CRT on $(\mathrm{p}=$ 0.00002; Figure 1). During exercise, left ventricular $\mathrm{dP} / \mathrm{dt}$ increased in all patients, whatever the pacing mode. With CRT off, exercise-induced changes in ERO 


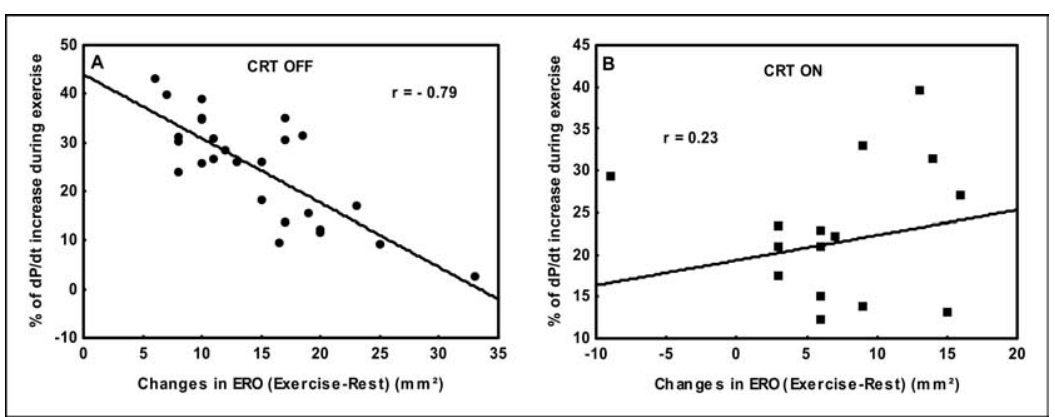

FIGURE 2. CRT off (A), CRT on (B): linear correlation between exercise-induced changes in ERO and the percentage of increase in left ventricular $\mathrm{dP} / \mathrm{dt}$.

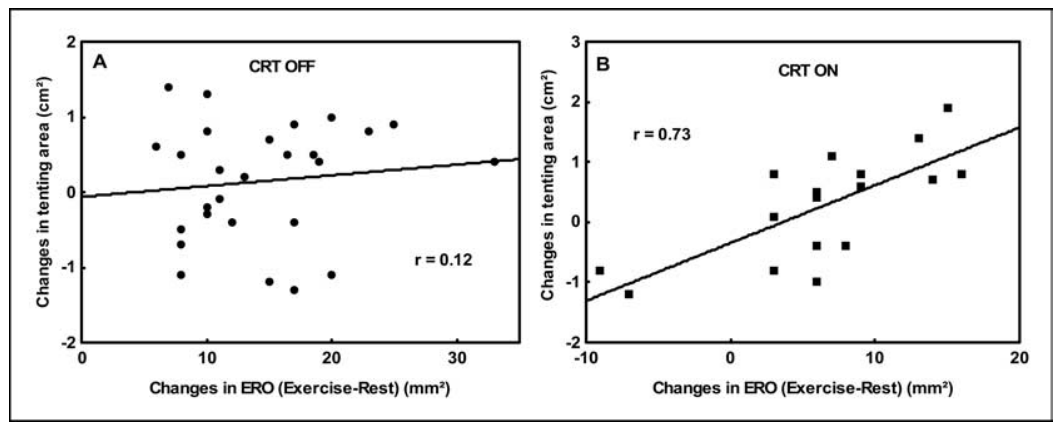

FIGURE 3. CRT off (A), CRT on (B): correlation between changes in ERO and changes in systolic tenting area during exercise.

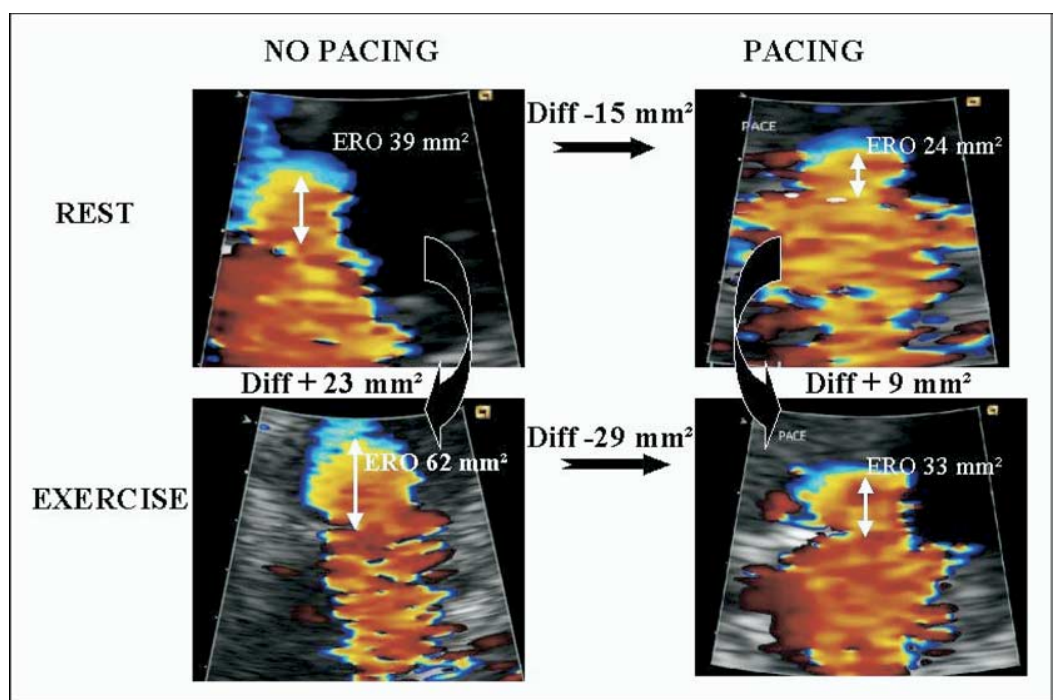

FIGURE 4. Proximal flow convergence region at rest and during exercise in a patient with CRT on (pacing) and CRT off (no pacing). At rest, ERO decreased by $15 \mathrm{~mm}^{2}$ with CRT on. During exercise, ERO markedly increased (by $23 \mathrm{~mm}^{2}$ ) with CRT off. The increment was less with CRT on $\left(+9 \mathrm{~mm}^{2}\right)$. The difference (diff) during exercise between CRT off and CRT on was $29 \mathrm{~mm}^{2}$.
The present study is the first to quantitatively assess the effects of CRT on MR during exercise. Biventricular pacing significantly reduces MR severity at rest and during exercise and its dynamic component, corresponding to exercise-induced changes in MR. At rest, the reduction of MR is mediated by an appropriate increase in left ventricular $\mathrm{dP} / \mathrm{dt}$, which facilitates effective mitral valve closure. The determinants of dynamic MR are different in synchronized versus nonsynchronized left ventricles. In synchronized left ventricles, exercise-induced increases in MR are related to changes in mitral valvular deformation, as estimated by the systolic tenting area. In nonsynchronized left ventricles, exercise-induced increases in MR are more specifically determined by inadequate increases in mitral closing force, as estimated by left ventricular $\mathrm{dP} / \mathrm{dt}$.

In this study, CRT reduced the degree of dynamic MR in all patients. At exercise, an increase in ERO by $\geq 13 \mathrm{~mm}^{2}$ was observed in 14 patients with CRT off but in only 4 patients with CRT on. Changes in ERO were related to the percentage of increase in left ventricular $\mathrm{dP} / \mathrm{dt}$ during exercise with CRT off but not with CRT on. Thus, in nonsynchronized patients, exercise-induced changes in mitral closing force represent the major determinant of exercise-induced changes in MR. The CRT-induced improvement of left ventricular synchronicity is probably maintained during exercise and might explain why there was no relation between residual exercise-induced changes in MR and increases in left ventricular $\mathrm{dP} / \mathrm{dt}$. Thus, in synchronized patients, residual dynamic MR is mainly determined by an increase in tethering forces induced by changes in mitral valvular deformation. were strongly related to the percentage of increase in left ventricular $\mathrm{dP} / \mathrm{dt}(\mathrm{r}=-0.79, \mathrm{p}<0.00001)$ (Figure 2$)$, whereas no correlation was observed with CRT on $(\mathrm{r}=$ $0.23, \mathrm{p}=\mathrm{NS}$; Figure 2). In contrast, exercise-induced changes in ERO were strongly related to changes in systolic tenting area with CRT on $(r=0.73, p=0.0009)$ but not during CRT off ( $\mathrm{r}=0.12, \mathrm{p}=\mathrm{NS}$; Figure 3$)$. Figure 4 shows an example of the effects of CRT on MR at rest and during exercise.
1. Cazeau S, Leclercq C, Lavergne T, Walker S, Varma C, Linde C, Garrigue S, Kappenberger L, Haywood GA, Santini M, et al, for the Multisite Stimulation in Cardimyopathies (MUSTIC) Study Investigators. Effects of multisite biventricular pacing in patients with heart failure and intraventricular conduction delay. N Engl J Med 2001;344:873-880.

2. Abraham WT, Fisher WG, Smith AL, Delurgio DB, Leon AR, Loh E, Kocovic DZ, Packer M, Clavell AL, Hayes DL, et al, for the Miracle Study Group. Cardiac resynchronization in chronic heart failure. $N$ Engl J Med 2002;346:1845-1853.

3. Bristow MR, Saxon LA, Boehmer J, Krueger S, Kass DA, De Marco T, Carson P, DiCarlo L, Demets D, White BG, et al, for the Comparison of Medical Therapy, Pacing and Defibrillation in Heart Failure (COMPANION) Investigators. Cardiac-resynchronization therapy with or without and implant- 
able defibrillator in advanced chronic heart failure. $N$ Engl $J$ Med 2004;350:2140-2150

4. Pitzalis MV, Iacoviello M, Romito R, Massari F, Rizzon B, Luzzi G, Guida P, Andriani A, Mastropasqua F, Rizzon P. Cardiac resynchronization therapy tailored by echocardiographic evaluation of ventricular asynchrony. J Am Coll Cardiol 2002;40:1615-1622.

5. Auricchio A, Stellbrink C, Sack S, Block M, Vogt J, Bakker P, Huth C, Schondube F, Wolfhard U, Bocker D, et al, Pacing Therapies in Congestive Heart Failure (PATH-CHF) Study Group. Long-term clinical effect of hemodynamically optimized cardiac resynchronization therapy in patients with heart failure and ventricular conduction delay. J Am Coll Cardiol 2002;39: 2026-2033

6. Breithardt OA, Sinha AM, Schwammenthal E, Bidaoui N, Markus KU, Franke A, Stellbrink C. Acute effects of cardiac resynchronization therapy on functional mitral regurgitation in advanced systolic heart failure. J Am Coll Cardiol 2003; 42:486-494
7. Lebrun F, Lancellotti P, Piérard LA. Quantitation of functional mitral regurgitation during bicycle exercise in patients with heart failure. J Am Coll Cardiol 2001;38:1685-1692

8. Lancellotti P, Troisfontaines P, Toussaint AC, Piérard LA. Prognostic importance of exercise-induced changes in mitral regurgitation in patients with chronic ischemic left ventricular dysfunction. Circulation 2003;108:1713-1717.

9. Bargiggia GS, Bertucci C, Recusani F, Raisaro A, de Servi S, Valdes-Cruz LM, Sahn DJ, Tronconi L. A new method for estimating left ventricular $\mathrm{dP} / \mathrm{dt}$ by continuous wave Doppler-echocardiography validation studies at cardiac catheterisation. Circulation 1989;80:1287-1292.

10. Yiu SF, Enriquez-Sarano M, Tribouilloy C, Seward JB, Tajik J. Determinants of the degree of functional mitral regurgitation in patients with systolic left ventricular dysfunction: a quantitative clinical study. Circulation 2000;102:1400-1406.

11. Lancellotti P, Lebrun F, Piérard LA. Determinants of exercise-induced changes in mitral regurgitation in patients with coronary artery disease and left ventricular dysfunction. J Am Coll Cardiol 2003;42:1921-1928.

\title{
Survey of the Use of Organic Nitrates for the Treatment of Chronic Congestive Heart Failure in the United States
}

\author{
Fahed Bitar, MD, Mohammed W. Akhter, MD, Salman Khan, MD, Harpreet Singh, MD, \\ and Uri Elkayam, MD
}

A survey of members of the Heart Failure Society of America revealed that despite their lack of approval by the United States Food and Drug Administration, nitrates are widely used in patients with chronic congestive heart failure (CHF). Most members reported using nitrates in patients with ischemic $(90 \%)$ and nonischemic $(81 \%)$ causes of chronic CHF, especially those with symptomatic $\mathrm{CHF}(43 \%$ reported using nitrates in $>50 \%$ of their patients with ischemic and $25 \%$ with nonischemic causes). Ninety-six percent reported using nitrates to reduce symptoms, $74 \%$ for hemodynamic improvement, $65 \%$ for better exercise tolerance, and only $14 \%$ for left ventricular reversed remodeling. Nitrates were always combined with hydralazine in $25 \%$ of patients and occasionally combined with hydralazine in 67\%. ( 2004 by Excerpta Medica Inc.

(Am J Cardiol 2004;94:1465-1468)

ganic nitrates were the first oral vasodilatory agents to be evaluated for the treatment of patients with chronic congestive heart failure (CHF). ${ }^{1,2}$ Early studies demonstrated beneficial hemodynamic effects, ${ }^{3,4}$ reduction of symptoms, better exercise tolerance,,$^{1,2}$ and, in combination with hydralazine, a superior effect on survival compared with placebo. ${ }^{2}$ Despite these data and because of a lack of larger scale studies, the use of nitrates for the treatment of patients

\footnotetext{
From the Heart Failure Program, Division of Cardiovascular Medicine, Department of Medicine, University of Southern California, Keck School of Medicine, Los Angeles, California. Dr. Elkayam's address is: Heart Failure Program, Division of Cardiovascular Medicine, University of Southern California, Keck School of Medicine, $1200 \mathrm{~N}$. State Street, Room 7440, Los Angeles, California 90033. E-mail: elkayam@usc.edu. Manuscript received March 1 1, 2004; revised manuscript received and accepted July 29, 2004.
}

with CHF has not been approved by the United States Food and Drug Administration. Despite this lack of approval, information from recent clinical trials have consistently suggested the widespread use of nitrates in the treatment of patients with CHF. ${ }^{3-5}$ The purpose of the present study was to evaluate the attitudes of physician members of the Heart Failure Society of America regarding the use of nitrates in the management of chronic CHF in the United States.

We obtained information about the use of nitrates in chronic CHF in the United States by sending questionnaires to 1,348 members of the Heart Failure Society of America with addresses in the United States. Responses were collected over the next 3 months (from March to May 2001). A database was created using Excel software (Microsoft Corporation, Redmond, Washington). Data were analyzed using Excel applications. The results were expressed as percentages of total responses. Responses were received from 308 members, of whom $91 \%$ indicated that they were using nitrates for the treatment of patients with $\mathrm{CHF}$ (Figure 1). Most respondents reported using nitrates to treat patients with CHF with ischemic and nonischemic causes (90\% and $81 \%$, respectively), although more respondents indicated the use of nitrates in $\geq 50 \%$ of their patients with ischemic compared with nonischemic causes ( $43 \%$ vs $25 \%$; Figure 2). Nitrates were used more often in patients with moderate to severe symptoms (New York Heart Association [NYHA] classes III and IV) compared with those with either no or only mild symptoms (NYHA classes I and II) (Figure 3). Ninety-six percent of respondents reported using nitrates for the reduction of symptoms, $74 \%$ for hemodynamic improvement, and $65 \%$ for improved exercise tolerance. Only $14 \%$ reported the use of nitrates for reverse remodeling of the left ventricle (Figure 4). 